\title{
Does Environmental Knowledge Matter? Social Influence and Pro-Environmental Behavior in University Students: An Indirect Effect Model
}

\author{
Gabriel Simiyu ${ }^{*}$, Valentine W. Kariuki ${ }^{2}$, Mwengei Ombaba ${ }^{3}$, Robert Otuya ${ }^{4}$ \\ 1,2,3,4 School of Business and Management Science, University of Eldoret, Kenya \\ *Corresponding author: gabrielsimiyu55@gmail.com
}

\section{Article History \\ Received 2021-09-14 \\ Revised 2021-011-11 \\ Revised 2021-12-13 \\ Accepted 2021-12-29 \\ Published 2022-01-01}

Keywords

Social influence

Environmental Knowledge

Pro-environmental behavior Environmental

Sustainability

University Students
Purpose- This study aims to provide an analytical framework that focuses on environmental knowledge as a mechanism through which social influence enhances pro-environmental behavior among university students.

Design/Methodology- The research employed quantitative strategy, cross-sectional survey design, and systematic random sampling techniques to obtain data from a sample of 335 university students using a structured self-administered questionnaire. The study hypotheses were tested using Hayes Process Macro vs. 3.5 (Model 4).

Findings- Results indicate that social influence strongly impacts students' environmental knowledge, and both variables significantly predict pro-environmental behavior. Environmental knowledge was discovered to be the strongest predictor of proenvironmental behavior among students. Finally, results show that environmental knowledge mediates the relationship between social influence and pro-environmental behavior, revealing a complimentary mediation model superior to the direct effect model.

Originality- These findings reveal that social influence and students' environmental knowledge have a strong influence in cultivating students' pro-environmental behavior. Furthermore, the complementary mediation model, which shows superior results than the direct effect model, contributes to the body of knowledge and offers new insights into theory and practice.

Practical Implications- Environmental sustainability may be positioned as a social trend by government and business agencies, such as a promotional campaign, workshops, and training to demonstrate and raise awareness about environmental issues. 


\section{Introduction}

The natural stability of our environment is being broken day by day due to the irresponsible environmental behavior of our society. The earth's health is deteriorating too fast. As we progress to Industry 2.0, the disastrous impact of rapidly expanding industrialization on nature is becoming increasingly dominant in human life. Disasters caused by climate change seem to be on the rise (Tian et al. 2020). We have witnessed the spread of lethal diseases among ordinary citizens who live near industrial zones and cannot move to safer areas due to lack of financial resources and government assistance (Donmez-Turan \& Kiliclar, 2021). Clark et al. (2019) and Chuchu et al. (2020) report that China and India have frequent major air and water pollution incidents, massive spikes in carbon emissions, depletion of agriculture, deforestation, reduced biodiversity, hundreds of cancer villages, and energy inefficient growth. According to Clark et al. (2019), it is estimated that over 700,000 people die each year due to causes related to the country's unhealthy environmental conditions. The health implications of high mortality rates, especially among children, are disheartening and can no longer be dismissed as a minor problem (Amoah \& Addoah, 2021). Environmental sustainability is therefore a big concern in both developed and developing countries (Khalique et al. 2020) which must be addressed immediately by all.

Recognizing the gravity of the emerging environmental challenges, scholars, intellectuals, scientists, policymakers, and governments worldwide are concerned and committed to seeking solutions (Pronello \& Gaborieau, 2018; Sousa et al. 2021). Unfortunately, the global environmental consciousness of this problem is shallow (Donmez-Turan \& Kiliclar, 2021). In this study, we argue that the more people are aware of the environmental issues caused by their behavior, the more they can accept responsibility for their actions and the critical role their behavior plays in eradicating these environmental problems. This, in effect, increases the probability of pro-environmental behavior and prompts people to act in an environmentally friendly manner by allowing personal norms to emerge (Donmez-Turan \& Kiliclar, 2021; Kim \& Stepchenkova, 2020; Li et al. 2020; Shin et al. 2017). However, as previously stated, the most significant impediment to the formation of proenvironmental behavior is a lack of knowledge (Donmez-Turan \& Kiliclar, 2021; Geng et al. 2017). It is on this premise, that the current study examines the role of environmental knowledge as a mechanism through which social influence (significant others) can cultivate or enhance pro-environmental behavior in university students.

Sousa et al. (2021) and Ahmad et al. (2021) argue that greenhouse gas emissions, deforestation, pollution, inadequate resource management, and climate change are only a few of the many environmental challenges requiring countries to meet their environmental governance responsibilities while still promoting economic growth without compromising ecological sustainability. However, concern for environmental sustainability takes a back seat in many developed nations as the emphasis is placed on economic growth (Clark et al. 2019). This notion must change. Governments, business organizations, and non-governmental agencies should take immediate steps to address climate change and its repercussions, including the development of human and institutional capital and mechanisms to facilitate effective environmental management to achieve the United Nations 2030 Agenda for Sustainable Development (Ahmad et al. 2021).

According to Sousa et al. (2021), due to the gravity of the environmental issues, there is an increasing focus on individual environmental actions, which may either be environmentally friendly or unfriendly. As a result, environmental preservation and conservation campaigns have risen to the top of the priority list of all stakeholders as a means of responding to this crisis (Kim \& Stepchenkova, 2020). Pro-environmental behaviors are described by Afsar et al. (2020) as the discretionary acts that contribute to the sustainability of the environment. On the other hand, Wong et al. (2021) define environmentally friendly behavior or proenvironmental behavior as behavior that deliberately seeks to minimize the adverse effects of one's activities on the ecological system. These pro-environmental behavior or actions are motivated by their social groups, environmental knowledge, value system, and other factors (Esfandiar et al. 2020; Wong et al. 2021). 


\section{Literature Review}

\section{Theoretical background and hypotheses development}

This study is guided by the Value Belief Norm theory, which takes into account the value and norm elements of the Norm Activation Model and the New Environmental Paradigm, that considers the general beliefs and concerns about the environment, as well as measures to combat environmental problems or environmental sustainability (Liobikienė \& Poškus, 2019; Nordfjærn \& Rundmo, 2019). This theory has been extensively used in analyzing sustainability (Ghazali et al. 2019; Liobikienè \& Poškus, 2019; Megeirhi et al. 2020; Wensing et al. 2019), among others. According to Value Belief Norm theory, values influence beliefs, which are assessed through the shared values, beliefs, and social relations (Chuang et al. 2020) that also affects students' environmental knowledge and understanding of their behavioral consequences, an assertion of accountability, which leads to personal norms regarding behavior, and, finally, predicts behavior.

\section{Social influence and Pro-Environmental Behavior}

Regardless of their background, humans are usually social creatures that tend to interact with groups of people to fulfill their human needs. In the process, they form social norms that reflect their collective consensus on what and how individual group members should behave, think, and do (Clark et al. 2019). Social influence and norms are strong predictors of human behavior and effective motivators of pro-environmental behavior. For example, Geng et al. (2017) found that social influence is an important motivator for shaping sustainable consumption behavior among Chinese consumers. As members of a social group or society, consumers gather and exchange knowledge among themselves. They consider and associate other people's perceptions, recommendations, or views on the product or service and evaluate them accordingly (Clark et al. 2019; Farrow et al. 2017; Goyal \& Goyal, 2021).

According to Han and Xu (2020)'s research, people who obtain recycling information from family and friends are more likely to recycle and have a much more significant influence on an individual's environmental behavior. It's been further noted in the work of Geng et al. (2017) that people who are close to you, such as family and friends, may impact your sustainable consumption habits. The authors suggest that governments and nongovernmental agencies may play a critical role in encouraging sustainable consumption behaviors among young Chinese consumers. In assessing the predicting factors affecting consumer motivation in purchasing electric vehicles, Cui et al. (2021) discovered that, in addition to environmental concern, price consciousness, openness to experience, and self-esteem, social influence plays a significant role in influencing the adoption of electric vehicles, which is regarded as one of the leading environmental solutions. On the other hand, Chen et al. (2016) contend that antecedents such as "social influence, environmental concern, self-image, and perceived environmental responsibility" inspire teenagers to purchase environmentally friendly goods.

In another study on the antecedents of green buying behavior in Pakistan, it was noted by Khalique et al. (2020) that green brands, green identification, and social influence were discovered to be significant predictors of green purchasing behavior. The authors further argue that consumers who associate themselves with people who care about the environment will always purchase green or environmentally friendly products. This highlights the strength of social influence in cultivating pro-environmental behavior. As a result, Khare (2019) argues that social influence is essential in persuading others of the functional nature of green brands and assisting such consumers in distinguishing between green and non-green goods.

In a comparative study between the young US and Chinese consumers, Blose et al. (2020) found that Chinese and American students may be receptive to grassroots attempts to encourage recycling behaviors through peer groups, friends, neighbors, and family ties. These groups (important others) significantly influence consumer decision-making, product awareness, and consumption habits. They also play an important role in shaping an 
identity of an individual, transmitting certain values and habits; thus, they are an information source that affects both environmental knowledge and pro-environmental behavior (Blose et al. 2020). A similar argument is also presented by Saeed et al. (2019), who found that positive and negative sustainability-related content or information on social media strongly impacts consumers' intentions to buy sustainable goods. Social media users create product-related content to inform one another about a company's sustainable practices and supply chain, thus enhancing environmental knowledge and pro-environmental behavior.

Finally, Matthies et al. (2012) observe that parents influence their children's pro-environmental behavior through sanctions, behavior, and information exchange concerning environmental problems. According to Matthies et al. (2012), parents and other significant people in the child's environment can help the child develop environmental knowledge, concern, and behaviors by serving as role models. Based on this discussion, we propose:

\section{H1: Social influence significantly predicts students' pro-environmental behavior.}

\section{H2: Social influence significantly influences students' environmental knowledge.}

\section{Environmental Knowledge and Pro-environmental Behavior}

Environmental knowledge is a general understanding of the natural environment's reality, principles, and relationships and its main ecosystems (Ahmad et al. 2021). It includes what people know about the environment, the main interactions that contribute to environmental issues or effects, the understanding of the whole processes, and the mutual obligations important for sustainable development. It is also referred to as environmental literacy in the work of Dresner et al. (2015), which implies the ability to perceive and understand the relative health of environmental systems and to take effective action to preserve, restore or improve health of those systems.

According to Amoah and Addoah (2021), it is expected that the more knowledgeable a person is, the more concerned they will be about environmental issues. People who are well-informed practice environmentally friendly behaviors in their daily lives, and they play a significant role in influencing environmental advancements through a variety of environmentally friendly behaviors (Kim et al. 2021). However, prior environmental knowledge studies have reported mixed results on taking the right steps to protect the environment. For example, Di Martino et al. (2019)'s study shows that consumers have moved from being motivated by knowledge of green products to environmental attitudes. According to the authors, consumer environmental knowledge no longer affects how they feel about green or environmentally friendly products. These contradictory findings are also reported in the work of Vicente-Molina et al. (2013), who indicated no significant relationship between environmental knowledge and pro-environmental behavior. Their findings suggest that the degree to which a person knows about a type of product or brand does not influence their green buying intentions. Additionally, Lee (2011) observed that environmental knowledge did not turn into a desire to pay more for eco-friendly apparel. This has been further reported in other recent studies (Chekima et al. 2016; Leonidou \& Skarmeas, 2017; Zarei \& Maleki, 2018) which have revealed that environmental knowledge does not significantly influence green consumer behavior.

While several studies have shown that knowledge alone is not enough to influence pro-environmental behavior, most studies have established that it is a prerequisite for a person's pro-environmental behavior (Vicente-Molina et al. 2018). According to Amoah and Addoah (2021)'s research on the relationship between environmental knowledge and pro-environmental behavior in developing countries, with a focus being on Ghana, environmental knowledge was found to be beneficial and statistically significant in understanding proenvironmental behavior. This is further supported by the findings of Chekima et al. (2016), which shows that customers with high environmental knowledge are more likely to purchase green or environmentally friendly 
products when faced with possible price barriers and understanding of green goods, indicating that overall environmental knowledge plays a significant role in green purchasing intentions.

Moreover, a study by Heo and Muralidharan (2019) found that ecological concern and knowledge are important predictors of young Millennials purchasing eco-friendly products. This is further supported by several other studies (Alhosseini Almodarresi et al. 2019; Boeve-de Pauw et al. 2019; Liobikiené \& Poškus, 2019; Mostafa, 2006; Otto \& Pensini, 2017), which have proposed that the promotion of environmental information and education can serve as practical tools both to improve environmental behavior as well as contribute to the reduction of environmental impacts. Consumers with greater knowledge and understanding of environmental issues are more likely to use green products, but lack of them contributes to insensitivity to environmental sustainability (Alhosseini Almodarresi et al. 2019). Green consumers are well-educated, younger, and superior to non-green consumers (Shukla, 2019). Therefore, it is argued in this study that individuals with greater environmental knowledge are more likely to behave responsibly towards protecting the environment.

Despite environmental knowledge being used as a predictor of pro-environmental behavior, very few studies have used it as a mediator or mechanism through which the outcome variable can be enhanced. For example, Ode and Ayavoo (2020) investigated the role of knowledge application as a mediator between knowledge management and firm innovation in Nigeria. Their findings confirm the mediation process on the study variables. In addition, Jung et al. (2011) examined the indirect effect of knowledge and efficacy on the link between communication and political participation in America. Results from the study support the idea that knowledge plays a significant role as a mediator. A study conducted in Malaysian Universities to assess academics' green behavior, the role of green human resource management, and environmental knowledge by Fawehinmi et al. (2020) discovered that knowledge mediates the process under investigation. This is further confirmed by Zheng et al. (2010), who discovered that experience or knowledge completely mediates the impact of organizational culture on organizational effectiveness. Thus, this study contends that favorable proenvironmental behaviors in young consumers can be effectively attained through social influences and environmental understanding or knowledge (Abrahamse \& Steg, 2013).

Given the variety of previous research findings, one important objective of this paper would be to determine how students' environmental knowledge mediates the relationship between social influence and proenvironmental behavior. Thus, we propose:

H3: Environmental knowledge significantly predicts students' pro-environmental behavior.

H4: Environmental knowledge mediates the relationship between social influence and students' pro-environmental knowledge.

\section{Covariates}

To minimize exogenous risks to the study model, three demographic factors, gender, age, and type of college students enrolled, were viewed as covariates. These variables have been found to significantly influence proenvironmental behavior (Hansmann et al. 2020; Mostafa, 2007; Patel et al. 2017).

\section{Research Methodology}

A closed-ended self-administered questionnaire was used to collect data from a sample size of 335 respondents who were University of Nairobi students in Kenya. The participants were grouped into six colleges (Health Sciences, Education and External Studies, Architecture and Engineering, Humanities and Social Sciences, Agriculture and Veterinary Science, Biological and physical). A cross-sectional survey design and systematic sampling technique were used in data collection. Three hundred eighty-four questionnaires were distributed, and three hundred thirty-five were returned, indicating an $87 \%$ response rate. According to the findings in 


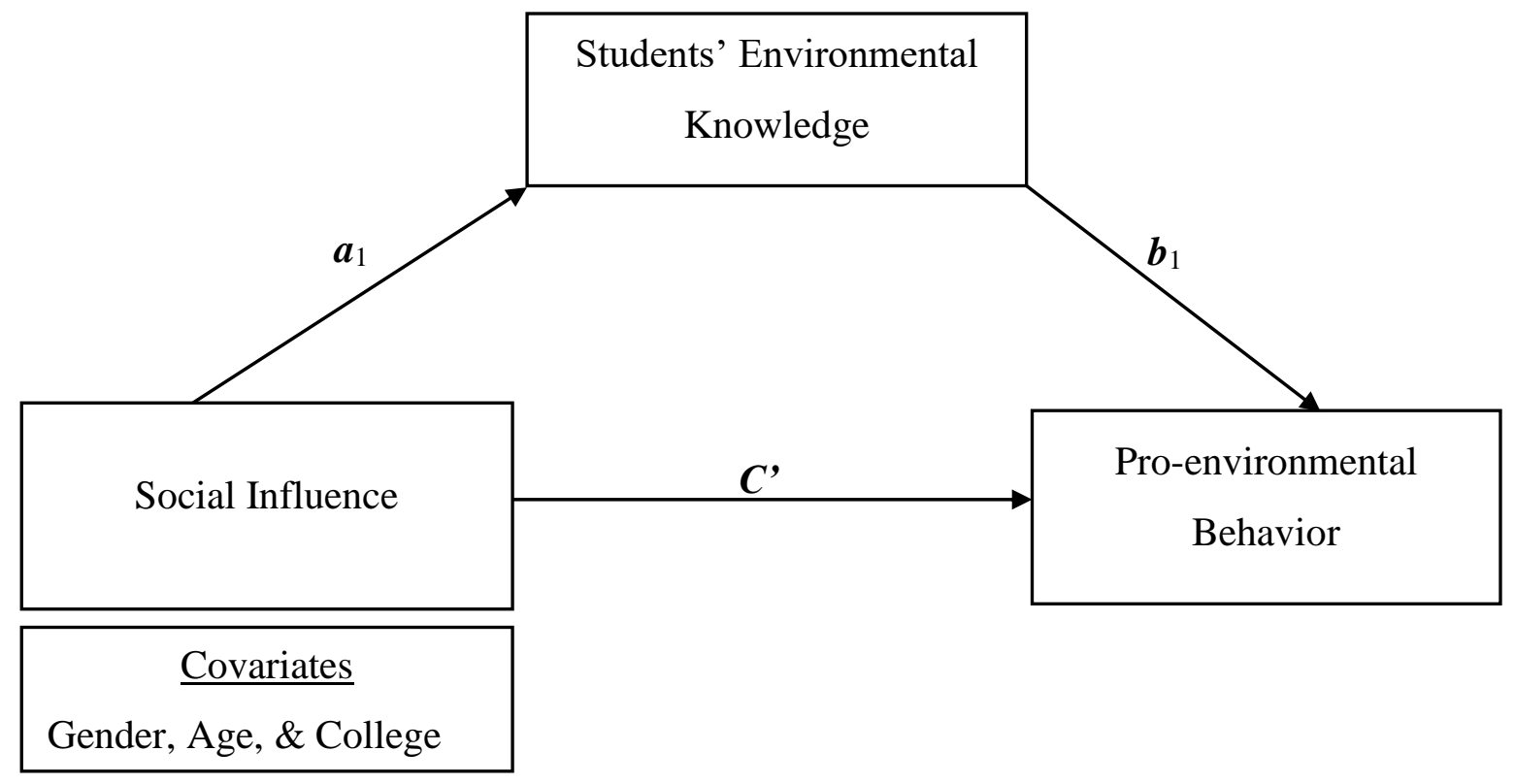

Figure 1: Conceptual Model

Source: Hayes (2018) Model 4

table I, $57.3 \%$ were males, and $42.7 \%$ were females; $69.2 \%$ were between the ages of 18 and 23; most respondents, $44.8 \%$, were from the College of Education and External Studies, with the least 4.8\% coming from the College of Biological and Physical Science.

Table 1: Respondents Demographic Profile

\begin{tabular}{llcc}
\hline Variable & Demographic factor & Respondents & \% no. of respondents \\
\hline Gender & Female & 143 & 42.7 \\
& Male & 192 & 57.3 \\
& Total & $\mathbf{3 3 5}$ & $\mathbf{1 0 0}$ \\
\hline Age & $18-23$ & 232 & 69.2 \\
& $24-29$ & 86 & 25.7 \\
& $30-35$ & 12 & 3.6 \\
& $36-41$ & 3 & .9 \\
& $42-47$ & 1 & .3 \\
& Above 48 & 1 & .3 \\
& Total & $\mathbf{3 3 5}$ & $\mathbf{1 0 0}$ \\
\hline College & Agriculture \& Veterinary Science & 47 & 14.0 \\
& Architecture \& Engineering & 19 & 5.7 \\
& Humanities and social & 84 & 25.0 \\
& Health Science & 19 & 5.7 \\
& Education \& External studies & 150 & 44.8 \\
& Biological \& Physical & 16 & 4.8 \\
& Total & $\mathbf{3 3 5}$ & $\mathbf{1 0 0}$ \\
\hline
\end{tabular}




\section{Measurement}

Variables in this study were assessed using several item scales adapted from previous studies with minor modifications to fit the current study context. Ten (10) items measuring pro-environmental behavior were adapted from Robertson and Barling (2017), five items (5) measuring social influence from Rehman and Dost (2013), and six (6) items measuring environmental knowledge from Mostafa (2007). Respondents were requested to indicate their level of agreement/disagreement with each item on a five Likert scale ranging from (1) 'strongly disagree' to (5) 'strongly agree.' Finally, covariates were measured as; gender " 0 " for females and " 1 " for males, age categorized in six (6) categories, and colleges categorized in seven different groups of " 1 to $7 "$.

\section{Results}

\section{Descriptive Statistics}

Findings of descriptive statistics for the study variables are presented in Table 2. Results show that social influence has the highest mean $=4.18$, with a standard deviation $=.526$. Environmental knowledge had the second highest mean $=3.87$, standard deviation $=.723$, while pro-environmental behavior had the least mean of 3.78 , standard deviation $=.612$, respectively. The reliability test results of the instrument are also presented in Table 2. Findings indicate that all variables had Cronbach's Alpha values above .5, with pro-environmental 10 items having the highest $\alpha=.914$, social influence $\alpha=.801$, and environmental knowledge having the least $\alpha=$. 543. The table further reveals results of correlation analysis which indicate that environmental knowledge has the highest relationship with pro-environmental behavior with $r=.638, p<.01$, while social influence had the least score $r=.557, p<.01$. Finally, findings also indicate that social influence has a significant relationship with environmental knowledge with $r=.389, p<.01$.

\section{Testing for Construct Validity}

Factor analysis was performed before testing the study hypotheses using the Principal Component extraction method with Varimax rotation analysis. Eigenvalues greater than 1 (one) was used to create and describe the study variables. Furthermore, any item that did not meet the requirements of having a factor loading value higher than. 5 and loading on only 1 (one) factor was excluded. Kaiser-Meyer-Olkin Measure of sampling adequacy (KMO) was used to confirm the appropriateness of factorability. As shown in Table 3, the KMO value was .875 , with Bartlet's Test of Sphericity revealing a Chi-Square of 2714.891 with $d f=210$, which was significant at $p=.000$. The table results show that three factors derived from twenty-one (21) items account for approximately $50 \%$ of the total variance. Factor 1 (one) had ten (10) items measuring pro-environmental behavior loaded on it. Findings show that this factor was responsible for approximately $28 \%$ of the variance. Five (5) items assessing social influence variable loaded on factor 2 (two) with results indicating that it roughly explains $15 \%$ percent of the variance. Finally, the results show that factor 3 (three) had three (3) items measuring environmental knowledge loaded on it and three others excluded because they did not load. This factor accounts for roughly $8 \%$ of the total variance.

Table 2: Findings of Descriptive statistics, Reliability test, and Correlation Analysis

\begin{tabular}{lcccccc}
\hline Variable & $\mathrm{M}$ & $\mathrm{SD}$ & $\alpha$ & Correlation & & \\
\hline Pro-environmental Behavior & 3.78 & .612 & .914 & 1 & & \\
Social Influence & 4.18 & .526 & .801 & $.557^{* *}$ & 1 & 1 \\
Environmental Knowledge & 3.87 & .723 & .543 & $.638^{* *}$ & $.389^{* *}$ & 1 \\
\hline
\end{tabular}

Note: Correlation is significant at ${ }^{* *}$ significant at 0.01 level (2-tailed). 
Table 3: Findings of Factor Analysis

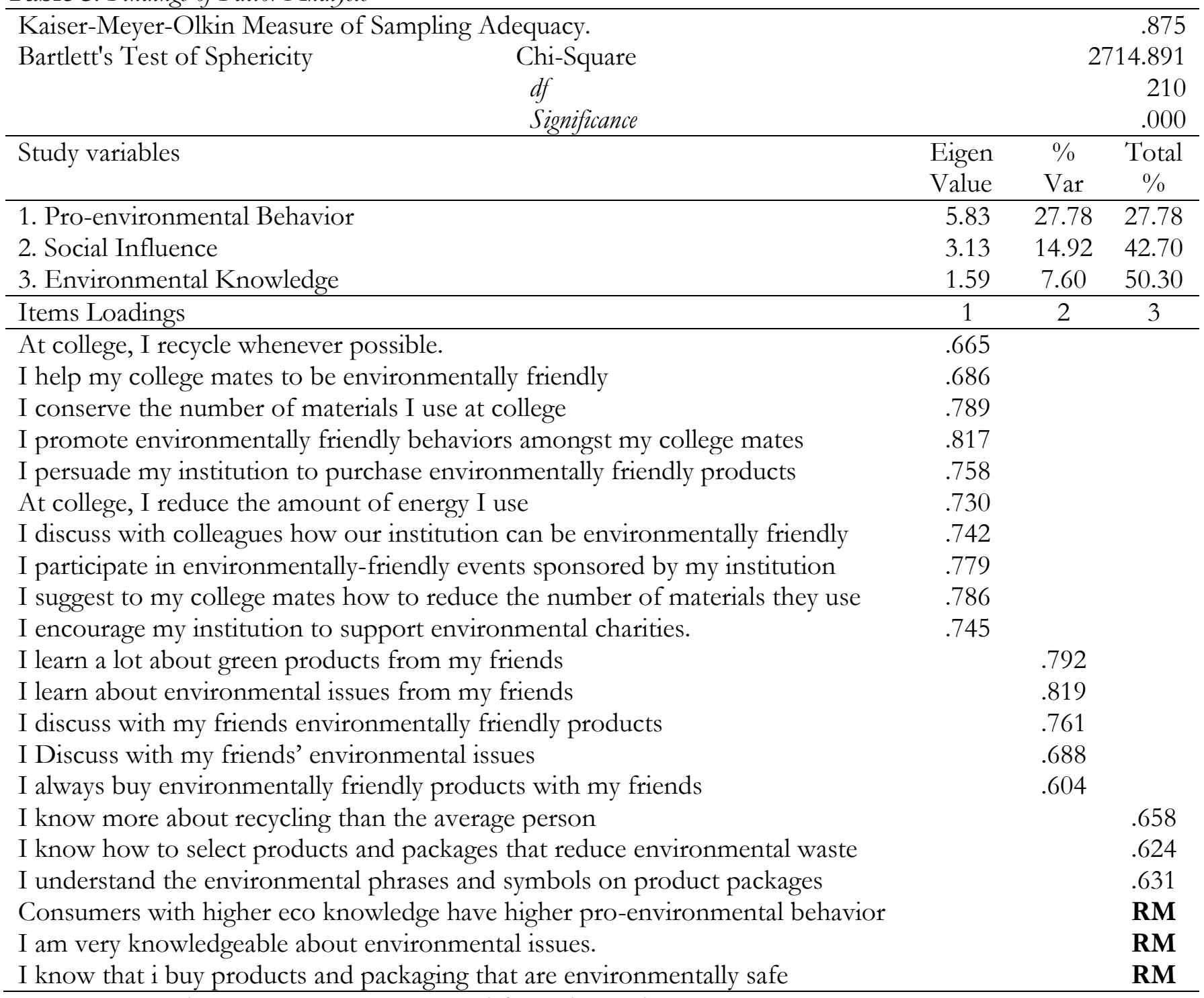

Note: Var = Variance, $\mathrm{RM}=$ Items removed from the study

\section{Hypotheses Testing}

In this study, four hypotheses were developed and tested using Hayes (2018) Process Macro vs 3.5 (Model 4). First, we investigated whether social influence would predict students' pro-environmental behavior; covariates were included in all analyses. Table 4, Model 2 findings show that the type of college a student attends has a significant but negative impact on their pro-environmental behavior $=-.168, p-v=.000$, as all other covariates were insignificant as indicated by $\mathrm{p}>.05$. However, results reveal that social influence positively and significantly influences pro-environmental behavior as shown by $\beta=.289$, $p-\nu=.000$ (path $\boldsymbol{C}^{\prime}$ of Figure 1). Results further show that this model accounts for $58.4 \%$ of the total variance in students' environmental behavior as indicated by $R^{2} .584$, with $F=92.260$, significant at $p-\mathrm{v}=.000$. Based on these results, $\mathrm{H} 1$ is supported by the study.

Second, we hypothesized that social influence would considerably impact students' environmental knowledge (H2). According to the findings in Table 4, Model 1, all covariates were insignificant. The results also show that social influence positively and significantly predicts students' pro-environmental behavior, as demonstrated 
by $=.396, p-v=.000$ (path $\boldsymbol{a}_{1}$ of Figure 1 of the conceptual model). The results show that this model has $\mathrm{R}^{2} .162$, $\mathrm{F}=15.897$, significant at $p-v=.000$. As per $\mathrm{R}^{2} .162$, the model explains $16.2 \%$ of students' environmental knowledge. Based on these results, hypothesis $\mathrm{H} 2$ is also supported.

Thirdly, the study sought to examine the influence of students' environmental knowledge on their proenvironmental behavior (indicated as path $\boldsymbol{b}_{1}$ of the conceptual model, Figure 1). Results reveals that environmental knowledge significantly influences pro-environmental behavior as shown by $\beta=.502, \mathrm{p}-\mathrm{v}=.000$, thus, hypothesis $\mathrm{H} 3$ is also supported by the study findings. The findings of this hypothesis are also shown in Model 2 of Table 4, indicated as $b_{1}$.

Finally, the study used MacKinnon's (2012) mediation guidelines to determine whether students' environmental knowledge mediates the link between social influence and students' pro-environmental behavior. These guidelines are;

1. The predictor variable $(\mathrm{X}=$ Social influence $)$ must significantly influence the mediator variable $(\mathrm{M}=$ Environmental Knowledge) shown as path $\boldsymbol{a}_{1}$ of Figure 1.

2. Mediator variable $(\mathrm{M}=$ Environmental knowledge) must significantly associate with the outcome variable $(\mathrm{Y}=$ Pro-environmental behavior $) \ldots$ path $\boldsymbol{b}_{1}$ of Figure 1.

3. Testing the association between the predictor variable $(\mathrm{X}=$ Social influence $)$ and the outcome variable $(\mathrm{Y}=$ Pro-environmental behavior) while controlling for the mediator variable $(\mathrm{M}=$ Environmental Knowledge) indicated as path $\boldsymbol{C}^{\prime}$ of Figure 1. This does not need to be significant for mediation to exist. This condition determines the nature of mediation in a study (Zhao et al. 2010). According to Zhao et al. (2010), the presence of both direct effect (path $\boldsymbol{C}^{\prime}$ ) and mediated effect $\left(\boldsymbol{a}_{1} \times\right.$ $\left.\boldsymbol{b}_{1}\right)$ with both having the same sign, either positive (+ve) or negative (-ve), reveals a complimentary mediation. However, if both exist (direct and indirect effect) but with opposite signs (one + ve and the other -ve sign), it indicates a Competitive mediation. Finally, the absence of a significant direct effect (path $\boldsymbol{C}$ ) and the presence of a significant $\left(\boldsymbol{a}_{\boldsymbol{1}} \times \boldsymbol{b}_{1}\right)$ reveals an Indirect-only mediation.

4. Finally, there should be a significant coefficient for the indirect effect of the predictor variable (social influence) on the outcome variable (pro-environmental behavior) via the mediator variable (environmental knowledge) $\left(\boldsymbol{a}_{1} \times \boldsymbol{b}_{1}\right)$. To determine if this last condition is met, the results of both confidence intervals (Lower and Upper Limit) must be zero.

Based on the above guideline, the study results in Table 4, Model 1 indicate that social influence (X) significantly influences environmental knowledge $(\mathrm{M})$, path $\boldsymbol{a}_{1}$ with $\beta=.396, p=.000$, thus the first condition ' 1 ' is confirmed. Results of Table 4, Model 2 shows that environmental knowledge predicts pro-environmental behavior, path $\boldsymbol{b}_{1}$ with $\beta=.502, p=.000$. Hence the second condition, ' 2 ,' is also confirmed. The same Model 2 reveals that social influence has a significant relationship with students' pro-environmental behavior, path $\boldsymbol{C}$ with $\beta=.289, p=.000$. This also confirms step three ' 3 .'

Following the four guidelines established by Zhao et al. (2010) discussed above, the study results revealed that the mean indirect effect from the bias-corrected percentile bias bootstrap analysis was positive and significant, $\boldsymbol{a}_{1} \times \boldsymbol{b}_{1}=.396 \times .502=.199, \mathrm{SE}=030, \mathrm{CI}=.141, .256$. Since both confidence intervals $(\mathrm{CI})$ do not cross zero, results confirm the presence of mediation.

Finally, results indicate both direct effect $(C=.289)$ and indirect effect $\left.\left(a_{1} \times b_{1}\right)=.289 \times .502=.199\right)$ with both results having the same positive $(+v e)$ signs, thus, revealing a complimentary mediation. Total Effect findings 
$($ direct + indirect effect $)=.289+.199=.488$ shown in Model 3 of the same table suggest that the two processes collectively make a significant contribution to the Total effect model, which seems to be a better model with a higher value $(\beta=.488)$ than when assessing the direct effect model alone $(\beta=.289)$. The covariate results show that the type of college a student currently enrolled in was significant with $\beta=-.161, p=.000$, as the rest were found to be insignificant. Furthermore, findings show that this model explains approximately $37 \%\left(\mathrm{R}^{2} .372\right)$ of the variance with a significant $F=48.973, p=.000$. Based on these results, hypothesis H4 is also supported by the study.

Table 4: Outcome of Regression and Hypotheses

\begin{tabular}{|c|c|c|c|c|c|c|}
\hline \multirow[t]{2}{*}{ Predictor } & \multicolumn{2}{|c|}{ Model 1 (EK) } & \multicolumn{2}{|c|}{ Model 2 (PEB) } & \multicolumn{2}{|c|}{ Model 3 (Total Effect) } \\
\hline & $\beta$ & $p-v$ & $\beta$ & $p-v$ & $\beta$ & $p-v$ \\
\hline Constant & -.069 & .705 & $.541 * * *$ & .000 & $.507 * * *$ & .001 \\
\hline Gender & .190 & .063 & .020 & .781 & .116 & .192 \\
\hline Age & -.067 & .375 & .059 & .271 & .025 & .700 \\
\hline College & .014 & .684 & $-.168 * * *$ & .000 & $-.161 * * *$ & .000 \\
\hline Social influence & $\boldsymbol{a}_{1}=.396 * * *$ & .000 & $C^{\prime}=.289^{* * *}$ & .000 & $.488^{* * *}$ & .000 \\
\hline Environ knowledge & - & - & $\boldsymbol{b}_{1}=.502 * * *$ & .000 & - & - \\
\hline$\overline{\mathrm{R}^{2}}$ & \multicolumn{2}{|c|}{.162} & \multicolumn{2}{|c|}{.584} & \multicolumn{2}{|c|}{.372} \\
\hline $\mathrm{F}$ & \multicolumn{2}{|c|}{$15.897 * * *$} & \multicolumn{2}{|c|}{$92.260 * * *$} & \multicolumn{2}{|c|}{$48.973 * * *$} \\
\hline
\end{tabular}

Mediation Results $=\quad \boldsymbol{a}_{1} \times \boldsymbol{b}_{1}=.396 \times .502=.199, \mathrm{SE}=030 \quad \mathrm{CI}=.141, .256$

Note: ${ }^{* * *}$ significant at $p<.001$, Environ knowledge, $\mathrm{EK}=$ Environmental Knowledge, PEB = Proenvironmental Behavior

\section{Discussion}

This study proposed three direct and one indirect hypotheses based on theoretical support, which was empirically tested using data obtained from University of Nairobi students as respondents. Hypothesis H1 postulated that social influence would predict students' pro-environmental behavior. Results from the analysis supported this hypothesis. These findings are in line with prior studies, which have indicated that consumers' behavior is frequently influenced by their social groups, and they would always want to associate with people who care about environmentally friendly products (Blose et al. 2020; Geng et al. 2017; Khalique et al. 2020; Khare, 2019; Li \& Wu, 2020; Thormann \& Wicker, 2021).

For example, Thormann and Wicker (2021) discovered that social norms (social influence) are significantly related to pro-environmental behavior in a study conducted in Germany on the determinants of proenvironmental behavior among voluntary sport club members. The study results are also consistent with the findings of Blose et al. (2020), who identified that social groups, acquaintances, neighbors, and family relationships play an essential role in cultivating recycling behaviors in the young US and Chinese consumers. This is further supported by Khalique et al. (2020), who observed that social influence significantly impacts green purchasing behavior in a study on consumers' attitudes toward green consumerism in Pakistan. Furthermore, regardless of their positive attitudes, a lack of social influence from important people may prevent students from participating in this process of pro-environmental sustainability (Liao \& Li, 2019).

The study findings on hypothesis $\mathrm{H} 2$ revealed that social influence positively and significantly influences students' environmental knowledge. As members of a social group or community, consumers gather and share information. They recognize and associate other people's perceptions of the product or service and evaluate them accordingly as to whether they are environmentally friendly or not (Clark et al. 2019). These findings are in line with Wan et al. (2017), whose study found that subjective norms may increase the likelihood of recycling 
for people who have a positive experience-based attitude and motivate people who have limited knowledge about the benefits of recycling behaviors.

This is further supported by the study findings of Matthies et al. (2012), who found that parents seemed to influence their children's recycling behavior through sanctions and their behavior, and that re-use of paper was primarily influenced through the communication of problem knowledge. Their findings revealed that the child's social and personal norms and the parent's descriptive norms account for $75 \%$ of the children's self-reported recycling behavior. Relating these findings to the current study, it implies that the more intense the information from peers, friends, family members, and neighbors, the better the understanding of the dangers of unsustainable environmental practices (Asih et al. 2020). Hence, social influence contributes significantly to increased environmental knowledge, which leads to pro-environmental behavior.

Thirdly, we hypothesized environmental knowledge would significantly predict students' pro-environmental behavior (H3). Results of the analysis also supported this hypothesis. This is consistent with many previous studies (Alhosseini Almodarresi et al. 2019; Aman et al. 2012; Boeve-de Pauw et al. 2019; Chekima et al. 2016; Mostafa, 2006; Shukla, 2019) among others, who found that the more informed and knowledgeable customers become, the greater their potential for environmental sustainability and the more they are willing to take proenvironmental action (Oğuz \& Kavas, 2010). However, our findings contradict several other studies (Chekima et al. 2016; Leonidou \& Skarmeas, 2017; Zarei \& Maleki, 2018), who found the nonsignificant role of environmental knowledge in influencing green consumerism.

Lastly, we sought to determine the mediating effect of environmental knowledge on the relationship between social influence and students' pro-environmental behavior $(\mathrm{H} 4)$. Our findings suggest that environmental knowledge can be a powerful tool or mechanism for social influence to cultivate pro-environmental behavior in young consumers. The study discovered a complementary mediation in which social influence and environmental knowledge contributed to a much more superior result than the direct effect model. This interplay has received little or no attention in the context of pro-environmental behavior, providing new insight and contributing to environmental sustainability literature and theory.

\section{Implications of The Study}

The obtained results of the current study can be used to infer meaningful theoretical, managerial, marketing, and policy makers' implications in fostering environmental sustainability. Theoretically, the findings have supported prior literature and the theory of Value-Belief-Norm, which explains how students' environmental knowledge is influenced by shared values and beliefs from significant others, which leads to enhanced personal norms regarding behavior, subsequently predicting pro-environmental behavior. Social influence from parents, peers, friends, teachers, and celebrities is critical in increasing an individual's motivation to engage in proenvironmental behavior because it increases the willingness of both those with extensive knowledge and those who are unaware of the benefits of environmental protection (Blose et al. 2020; Khare, 2019; Wan et al. 2017). As a result, both government and business agencies may position environmental sustainability as a social trend, for example, through a promotional campaigns, workshops, and training to demonstrate and raise awareness about environmental issues (Wan et al., 2017).

Secondly, environmental knowledge has been recognized as a powerful predictor of pro-environmental behavior in this study as indicated by $\beta=.502, p<.05$. In addition, it has been proved to be a robust mechanism (mediator variable) through which social influence can enhance pro-environmental behavior. These results demonstrate that when students receive adequate support, awareness, encouragement, and involvement of ecological sustainability from parents, teachers, peers, or friends, their environmental knowledge ignites environmentally friendly behavior (Fawehinmi et al. 2020). Thus, young consumers can be involved in environmental initiatives to help raise their awareness or understanding through social networking sites and 
consumer blogs to spread the word about the environmental benefits of sustainability (Khare, 2019). Additionally, marketers should identify appropriate messages that provide background information regarding environmental issues about products or services or organizations and illustrate how such a product, service, or organization can help to alleviate environmental problems (Heo \& Muralidharan, 2019).

\section{Limitations and Future studies}

This study has some limitations that can be used for future research. The current study was conducted in Kenya at a single public university with six different colleges. Before making broad generalizations, a broad scope is recommended. Furthermore, due to differences in cultural backgrounds, this study cannot be generalized to other countries; consequently, caution should be exercised when interpreting this study's findings. Additionally, the methodology used in this study is cross-sectional, which does not reflect how the processes investigated in this study perform over time. A longitudinal research design could be used to provide more justification for the assertions made in this study.

\section{Conclusion}

This study provides some useful insights into cultivating pro-environmental behavior in young consumers in developing economies. According to the study's findings, social influence and environmental knowledge significantly predict pro-environmental behavior. The findings also revealed that environmental knowledge plays an important role as a mediator in enhancing the relationship between social influence and students' proenvironmental behavior, revealing a complimentary mediation model that is superior to the direct effect model when tested.

Funding: No funds, grants, or other support was received.

Acknowledgments: We thank God for His Grace and Mercy in guiding us in the entire process of carrying out and writing this research work.

Conflicts of Interest: The authors declare no conflict of interest.

\section{References}

Abrahamse, W., \& Steg, L. (2013). Social influence approaches to encourage resource conservation: A metaanalysis. Global environmental change, 23(6), 1773-1785.

Afsar, B., Maqsoom, A., Shahjehan, A., Afridi, S. A., Nawaz, A., \& Fazliani, H. (2020). Responsible leadership and employee's proenvironmental behavior: The role of organizational commitment, green shared vision, and internal environmental locus of control. Corporate Social Responsibility and Environmental Management, 27(1), 297-312.

Ahmad, S., Islam, T., Sadiq, M., \& Kaleem, A. (2021). Promoting green behavior through ethical leadership: a model of green human resource management and environmental knowledge. Leadership \& Organization Development Journal, 42(4), 531-547. doi: 10.1108/lodj-01-2020-0024

Alhosseini Almodarresi, S. M., Tabataba'i-Nasab, S. M., Bagheri Garabollagh, H., \& Mohammadi, F. (2019). Does citizenship behavior have a role in changing attitude toward green products? International Journal of Management Science and Engineering Management, 14(4), 284-292.

Aman, A. L., Harun, A., \& Hussein, Z. (2012). The influence of environmental knowledge and concern on green purchase intention the role of attitude as a mediating variable. British Journal of Arts and Social Sciences, 7(2), 145-167.

Amoah, A., \& Addoah, T. (2021). Does environmental knowledge drive pro-environmental behaviour in developing countries? Evidence from households in Ghana. Environment, Development and Sustainability, 23(2), 2719-2738. 
Asih, D., Setini, M., Soelton, M., Muna, N., Putra, I., Darma, D., \& Judiarni, J. (2020). Predicting green product consumption using theory of planned behavior and reasoned action. Management Science Letters, 10(14), 3367-3374.

Blose, J. E., Mack, R. W., Pitts, R. E., \& Xie, H. Y. (2020). Exploring young US and Chinese consumers' motivations to recycle. Journal of International Consumer Marketing, 32(1), 33-46.

Boeve-de Pauw, J., Van Hoof, J., \& Van Petegem, P. (2019). Effective field trips in nature: the interplay between novelty and learning. Journal of Biological Education, 53(1), 21-33.

Chekima, B., Chekima, S., Syed Khalid Wafa, S. A. W., Igau, O. A., \& Sondoh Jr, S. L. (2016). Sustainable consumption: the effects of knowledge, cultural values, environmental advertising, and demographics. International Journal of Sustainable Development \& World Ecology, 23(2), 210-220.

Chekima, B., Wafa, S. A. W. S. K., Igau, O. A., Chekima, S., \& Sondoh Jr, S. L. (2016). Examining green consumerism motivational drivers: does premium price and demographics matter to green purchasing? Journal of Cleaner Production, 112, 3436-3450.

Chen, Y.-S., Tien, W.-P., Lee, Y.-I., \& Tsai, M.-L. (2016). Greenwash and green brand equity. Paper presented at the 2016 Portland International Conference on Management of Engineering and Technology (PICMET).

Chuang, F., Manley, E., \& Petersen, A. (2020). The role of worldviews in the governance of sustainable mobility. Proceedings of the National Academy of Sciences, 117(8), 4034-4042.

Chuchu, T., Maziriri, E. T., \& Mototo, L. (2020). A Review of the Impact of Consumerism, Recycling and Pollution: Evidence from Southeast Asia: 1999 to 2019. Journal of Environmental Management \& Tourism, 11(1 (41)), 23-28.

Clark, R. A., Haytko, D. L., Hermans, C. M., \& Simmers, C. S. (2019). Social influence on green consumerism: country and gender comparisons between China and the United States. Journal of International Consumer Marketing, 31(3), 177-190.

Cui, L., Wang, Y., Chen, W., Wen, W., \& Han, M. S. (2021). Predicting determinants of consumers' purchase motivation for electric vehicles: An application of Maslow's hierarchy of needs model. Energy Policy, 151, 112167. doi: https://doi.org/10.1016/j.enpol.2021.112167

Di Martino, J., Nanere, M. G., \& DSouza, C. (2019). The effect of pro-environmental attitudes and eco-labelling information on green purchasing decisions in Australia. Journal of Nonprofit \& Public Sector Marketing, 31(2), 201-225.

Donmez-Turan, A., \& Kiliclar, I. E. (2021). The analysis of pro-environmental behaviour based on ecological worldviews, environmental training/knowledge and goal frames. Journal of Cleaner Production, 279, 123518.

Dresner, M., Handelman, C., Braun, S., \& Rollwagen-Bollens, G. (2015). Environmental identity, proenvironmental behaviors, and civic engagement of volunteer stewards in Portland area parks. Environmental Education Research, 21(7), 991-1010.

Esfandiar, K., Dowling, R., Pearce, J., \& Goh, E. (2020). Personal norms and the adoption of proenvironmental binning behaviour in national parks: An integrated structural model approach. Journal of Sustainable Tourism, 28(1), 10-32.

Farrow, K., Grolleau, G., \& Ibanez, L. (2017). Social norms and pro-environmental behavior: A review of the evidence. Ecological Economics, 140, 1-13.

Fawehinmi, O., Yusliza, M. Y., Mohamad, Z., Faezah, J. N., \& Muhammad, Z. (2020). Assessing the green behaviour of academics: The role of green human resource management and environmental knowledge. International Journal of Manpower, 41(7), 879-900.

Geng, D., Liu, J., \& Zhu, Q. (2017). Motivating sustainable consumption among Chinese adolescents: An empirical examination. Journal of Cleaner Production, 141, 315-322. 
Ghazali, E. M., Nguyen, B., Mutum, D. S., \& Yap, S.-F. (2019). Pro-environmental behaviours and ValueBelief-Norm theory: Assessing unobserved heterogeneity of two ethnic groups. Sustainability, 11(12), 3237.

Goyal, M., \& Goyal, R. K. (2021). Confirming Antecedents of Green Consumption Intention: A Sustainable Model for Food Aggregators. IETE Journal of Research, 67(5), 634-645. doi: 10.1080/03772063.2021.1906336

Han, R., \& Xu, J. (2020). A Comparative study of the role of interpersonal communication, traditional media and social media in pro-environmental behavior: A China-based study. International journal of environmental research and public health, 17(6), 1883.

Hansmann, R., Laurenti, R., Mehdi, T., \& Binder, C. R. (2020). Determinants of pro-environmental behavior: A comparison of university students and staff from diverse faculties at a Swiss University. Journal of Cleaner Production, 268, 121864. doi: https://doi.org/10.1016/j.jclepro.2020.121864

Hayes, A. F. (2018). Introduction to mediation, moderation, and conditional process analysis second edition: A regression-based approach.: New York, NY: Guilford Publications, Inc.

Heo, J., \& Muralidharan, S. (2019). What triggers young Millennials to purchase eco-friendly products?: the interrelationships among knowledge, perceived consumer effectiveness, and environmental concern. Journal of Marketing Communications, 25(4), 421-437.

Jung, N., Kim, Y., \& De Zúniga, H. G. (2011). The mediating role of knowledge and efficacy in the effects of communication on political participation. Mass Communication and Society, 14(4), 407-430.

Khalique, M., Iftikhar, S., bin Yaacob, M. R., \& Tahir, A. (2020). Antecedents and Mediating Role of Green Buying Behavior. Market Forces, 15(2), 22-22.

Khare, A. (2019). Green Apparel Buying: Role of Past Behavior, Knowledge and Peer Influence in the Assessment of Green Apparel Perceived Benefits. Journal of International Consumer Marketing, 1-17. doi: 10.1080/08961530.2019.1635553

Kim, M.-S., \& Stepchenkova, S. (2020). Altruistic values and environmental knowledge as triggers of proenvironmental behavior among tourists. Current Issues in Tourism, 23(13), 1575-1580.

Kim, Y. D., Nam, C., \& LaPlaca, A. M. (2021). Marketing and communicating sustainability through college athletics: the effects of pro-environmental initiatives on the belief-attitude-intention hierarchy. Journal of Marketing for Higher Education, 1-21. doi: 10.1080/08841241.2021.1892897

Lee, S. (2011). Consumers' value, environmental consciousness, and willingness to pay more toward greenapparel products. Journal of Global Fashion Marketing, 2(3), 161-169.

Leonidou, C. N., \& Skarmeas, D. (2017). Gray shades of green: Causes and consequences of green skepticism. Journal of business ethics, 144(2), 401-415.

Li, Q., \& Wu, M. (2020). Tourists' pro-environmental behaviour in travel destinations: Benchmarking the power of social interaction and individual attitude. Journal of Sustainable Tourism, 28(9), 1371-1389.

Li, W., Lee, P. K., Chan, J. C., \& Tan, H. (2020). Cultivating environmentally responsible citizens in a local university in Hong Kong-evaluating the cognitive, attitudinal, and behavioral outcomes. International Research in Geographical and Environmental Education, 29(4), 301-315.

Liao, C., \& Li, H. (2019). Environmental Education, Knowledge, and High School Students' Intention toward Separation of Solid Waste on Campus. International Journal of Environmental Research and Public Health, 16(9), 1659; doi: 10.3390/ijerph16091659

Liobikiené, G., \& Poškus, M. S. (2019). The Importance of Environmental Knowledge for Private and Public Sphere Pro-Environmental Behavior: Modifying the Value-Belief-Norm Theory. Sustainability, 11(12), 3324.

MacKinnon, D. (2012). Introduction to statistical mediation analysis: Routledge. 
Matthies, E., Selge, S., \& Klöckner, C. A. (2012). The role of parental behaviour for the development of behaviour specific environmental norms-The example of recycling and re-use behaviour. Journal of Environmental Psychology, 32(3), 277-284.

Megeirhi, H. A., Woosnam, K. M., Ribeiro, M. A., Ramkissoon, H., \& Denley, T. J. (2020). Employing a valuebelief-norm framework to gauge Carthage residents' intentions to support sustainable cultural heritage tourism. Journal of Sustainable Tourism, 28(9), 1351-1370.

Mostafa, M. M. (2006). Antecedents of Egyptian consumers' green purchase intentions: A hierarchical multivariate regression model. Journal of international consumer marketing, 19(2), 97-126.

Mostafa, M. M. (2007). Gender differences in Egyptian consumers' green purchase behaviour: the effects of environmental knowledge, concern and attitude. International Journal of Consumer Studies, 31(3), 220 229.

Nordfjærn, T., \& Rundmo, T. (2019). Acceptance of disincentives to driving and pro-environmental transport intentions: the role of value structure, environmental beliefs and norm activation. Transportation, 46(6), 2381-2396.

Ode, E., \& Ayavoo, R. (2020). The mediating role of knowledge application in the relationship between knowledge management practices and firm innovation. Journal of Innovation \& Knowledge, 5(3), 210 218.

Oğuz, D., \& Kavas, S. (2010). Environmental awareness of university students in Ankara, Turkey. African Journal of Agricultural Research, 5(19), 2629-2636.

Otto, S., \& Pensini, P. (2017). Nature-based environmental education of children: Environmental knowledge and connectedness to nature, together, are related to ecological behaviour. Global Environmental Change, 47, 88-94.

Patel, J., Modi, A., \& Paul, J. (2017). Pro-environmental behavior and socio-demographic factors in an emerging market. Asian Journal of Business Ethics, 6(2), 189-214.

Pronello, C., \& Gaborieau, J.-B. (2018). Engaging in pro-environment travel behaviour research from a psychosocial perspective: A review of behavioural variables and theories. Sustainability, 10(7), 2412.

Rehman, Z.-u., \& Dost, M. B. (2013). Conceptualizing green purchase intention in emerging markets: An empirical analysis on Pakistan. Paper presented at the The 2013 WEI International Academic Conference Proceedings.

Robertson, J. L., \& Barling, J. (2017). Toward a new measure of organizational environmental citizenship behavior. Journal of Business Research, 75, 57-66.

Saeed, M. A., Farooq, A., Kersten, W., \& Abdelaziz, S. I. B. (2019). Sustainable product purchase: does information about product sustainability on social media affect purchase behavior? Asian Journal of Sustainability and Social Responsibility, 4(1), 1-18.

Shin, Y. H., Im, J., Jung, S. E., \& Severt, K. (2017). Consumers' willingness to patronize locally sourced restaurants: The impact of environmental concern, environmental knowledge, and ecological behavior. Journal of Hospitality Marketing \& Management, 26(6), 644-658.

Shukla, S. (2019). A Study on Millennial Purchase Intention of Green Products in India: Applying Extended Theory of Planned Behavior Model. Journal of Asia-Pacific Business, 20(4), 322-350.

Sousa, S., Correia, E., Leite, J., \& Viseu, C. (2021). Environmental knowledge, attitudes and behavior of higher education students: a case study in Portugal. International Research in Geographical and Environmental Education, 30(4), 348-365. doi: 10.1080/10382046.2020.1838122

Thormann, T. F., \& Wicker, P. (2021). Determinants of pro-environmental behavior among voluntary sport club members. German Journal of Exercise and Sport Research, 51(1), 29-38.

Tian, H., Zhang, J., \& Li, J. (2020). The relationship between pro-environmental attitude and employee green behavior: the role of motivational states and green work climate perceptions. Environmental Science and Pollution Research, 27(7), 7341-7352. 
Vicente-Molina, M., Fernández-Sainz, A., \& Izagirre-Olaizola, J. (2018). Does gender make a difference in proenvironmental behavior? The case of the Basque Country University students. Journal of Cleaner Production, 176, 89-98.

Vicente-Molina, M. A., Fernández-Sáinz, A., \& Izagirre-Olaizola, J. (2013). Environmental knowledge and other variables affecting pro-environmental behaviour: comparison of university students from emerging and advanced countries. Journal of Cleaner Production, 61, 130-138.

Wan, C., Shen, G. Q., \& Choi, S. (2017). Experiential and instrumental attitudes: Interaction effect of attitude and subjective norm on recycling intention. Journal of Environmental Psychology, 50, 69-79.

Wensing, J., Carraresi, L., \& Bröring, S. (2019). Do pro-environmental values, beliefs and norms drive farmers' interest in novel practices fostering the Bioeconomy? Journal of environmental management, 232, 858867.

Wong, I. A., Wan, Y. K. P., Huang, G. I., \& Qi, S. (2021). Green event directed pro-environmental behavior: an application of goal systems theory. Journal of Sustainable Tourism, 29(11-12), 1948-1969. doi: 10.1080/09669582.2020.1770770

Zarei, A., \& Maleki, F. (2018). From decision to run: the moderating role of green skepticism. Journal of Food Products Marketing, 24(1), 96-116.

Zhao, X., Lynch Jr, J. G., \& Chen, Q. (2010). Reconsidering Baron and Kenny: Myths and truths about mediation analysis. Journal of consumer research, 37(2), 197-206.

Zheng, W., Yang, B., \& McLean, G. N. (2010). Linking organizational culture, structure, strategy, and organizational effectiveness: Mediating role of knowledge management. Journal of Business research, 63(7), 763-771. 